\title{
Corticosteroid therapy can be delayed but not omitted in idiopathic tubulointerstitial nephritis
}

\author{
Timo Jahnukainen • Kai Rönnholm • \\ Marja Ala-Houhala $\cdot$ Matti Nuutinen
}

Received: 4 November 2013 /Revised: 4 November 2013 / Accepted: 7 November 2013 /Published online: 21 December 2013

(C) IPNA 2013

Dear Sirs,

Dr. Bensman has pointed out an important concern about the necessity of glucocorticoid treatment in selective patients presenting with tubulointerstitial nephritis [1]. In our study [2], all patients had an idiopathic tubulointerstitial nephritis. Sarcoidosis and other underlying etiological factors were ruled out as mentioned in the article. We fully agree with Dr. Bensman's concern and want to highlight that it is of great importance to exclude other conditions that require prompt treatment with glucocorticoids or other immunosuppressive drugs. According to our clinical practice, glucocorticoid therapy is started even in TIN patients without underlying disease if (1) plasma creatinine is constantly increasing, (2) there are other signs of progression of the disease, or (3) the patient does not show any signs of clinical improvement during 2 weeks of follow-up.

\section{References}

1. Bensman A (2013) Corticosteroids in tubulointerstitial nephritis. Pediatr Nephrol. doi:10.1007/s00467-013-2714-2

2. Jahnukainen T, Saarela V, Arikoski P, Ylinen E, Rönnholm K, Ala-Houhala M, Nuutinen M (2013) Prednisone in the treatment of tubulointerstitial nephritis in children. Pediatr Nephrol $28: 1253-1260$

T. Jahnukainen $(\bowtie) \cdot K$. Rönnholm

Department of Pediatric Nephrology and Transplantation, Children's

Hospital, Helsinki University Central Hospital and University of

Helsinki, Helsinki, Finland

e-mail: timo.jahnukainen@hus.fi

M. Ala-Houhala

Department of Pediatrics, Tampere University Hospital,

Tampere, Finland

M. Nuutinen

Department of Paediatrics and Adolescence, Oulu University

Hospital, Oulu, Finland 